\title{
SMALL BUSINESS LIFE CYCLE: STATICS AND DYNAMICS (S\&D) MODEL
} pages: $48-58$

\author{
MAREK MATEJun, ZdENĚK MiKOlÁŠ
}

\begin{abstract}
A B S T R A C T
The aim of the paper is the presentation of theoretical foundations and the structure of original, 8-stage statics and dynamics model in the small business life cycle. Based on theoretical considerations, two hypotheses concerning the impact of dynamic and static nature of the life-cycle stages on selected determinants and effects of SMEs' development were formulated. The hypotheses were verified based on the results of the survey conducted on a sample of 1,741 SMEs from 22 countries of the European Union. The results indicate that companies in the dynamic life-cycle stages are run by more enterprising owners, operate in more promising markets with a higher potential and make greater use of market niches thus limiting the level of competition. At the same time, such companies are characterised by higher levels of flexibility and involvement in innovative activities, which translates into obtaining a significantly higher level of business performance, in the area of quantitative as well as qualitative results.
\end{abstract}

KEY WORDS

small business, micro, small and medium-sized enterprises, business life cycle, business performance

DOI: $10.1515 /$ emj-2017-0030
Corresponding author:

Marek Matejun

Lodz University of Technology, Faculty of Management and Production Engineering, Department of Management, Poland e-mail: matejun@p.lodz.pl

Zdeněk Mikoláš

College of Entrepreneurship and Law, Department of Entrepreneurship and Management, Czechia e-mail: zdenek.mikolas@vspp.cz

\section{INTRODUCTION}

Organisational life cycle models are a group of useful management tools employed for description, interpretation and prediction of the course of business development stages. Many models consider the specificity of small business. This specificity primarily includes the focus on the initial stages of the life cycle, and also assumes the existence of changes that lead to leaving the population of micro, small and medium-sized enterprises (SMEs), and transitioning to the class of large enterprises (LEs). This enables the determination of development stages specific to small business. One of the criteria for their determination may be the division into the static and dynamic stages, which expresses the diversity 
observed in the intensity of development processes, market activity and the investment scope.

Based on the above, the aim of the paper is the presentation of theoretical foundations and the structure of original, 8-stage statics and dynamics model in the small business life cycle. Two research hypotheses were formulated. The results of the survey aimed at the description and interpretation of selected determinants and effects of SMEs' development processes in dynamic and static life-cycle stages, were used for the empirical illustration of the considerations. The research was conducted on a sample of 1,741 micro, small and medium-sized enterprises from 22 countries of the European Union. The results indicate that companies in the dynamic life-cycle stages are run by more enterprising owners, operate in more promising markets with a higher potential and make greater use of market niches thus limiting the level of competition. At the same time, such companies are characterised by higher levels of flexibility and involvement in innovative activities, which translates into obtaining a significantly higher level of business performance, in the area of quantitative as well as qualitative results.

\section{LITERATURE REVIEW}

Organisational life cycle (OLC) models are used to describe, interpret and predict the course of development stages of modern enterprises. In terms of the concept, they are derived from the theory of biological determinism, interpreting organisational reality with the use of perception specific to the natural world (Samuel, 2012). Due to this fact, these models allow a metaphorical comparison of organisations to living organisms that are born, grow, develop, go through certain changes in life, and then die. Thus, OLC models accentuate volatility and relative impermanence of economic organisations, at the same time stressing the dynamic nature of development processes occurring in modern enterprises.

There are many proposed stage models of the organisational life cycle in management sciences. Based on the literature review of 1962-2006, Levie and Lichtenstein (2010) identified 104 such models, covering from 2 to 11 stages $(\mathrm{m}=4.3)$. Tam and Gray (2016) focused on the existing theoretical achievements in the field of OLC models encompassing more than sixty years and synthesised them into four major periods: primitive (the 1950s-1960s), contextual (the 1970s), enhanced (the 1980s), and validated (the 1990s and beyond). In each of these periods, both the number and complexity of the proposed models increased, offering additional cognitive values and applications.

The substantive justification of OLC models is derived from the concept of the s-curve model introduced into economic sciences by Griliches (1957) and developed by Mansfield (1961). The general form of the model is represented by the proposal formulated by Jackson and Morgan (1982) which expresses the general model of the social systems development cycle involving the following successive stages:

- creation and expansion,

- stabilisation and dynamic equilibrium,

- change or decline and dissolution.

Some of the proposed OLC models consider the specificity of small business, which is especially useful for description, interpretation and prediction of development processes of micro, small and medium-sized enterprises. 125 million of SME companies play a significant social and economic role in most developed and developing countries (Kushnir, Mirmulstein \& Ramalho, 2010). They are also essential for the success and development of the European Union (Lukács, 2005; Autio, 2016), where they build efficiency and competitiveness of economy as the main source of new jobs and innovative ideas related to entrepreneurship and economic activity (Floyd \& McManus, 2005). To distinguish SMEs out of the entire population of business entities, specific quantitative and qualitative criteria are used. In the European Union, these criteria are formulated in the form of a uniform, formal definition adopted by the European Commission (2015). This definition sets the upper limits of small business quantitative criteria to 249 employees (FTE) and an annual turnover at the level of EUR 50 million or a balance sheet total of EUR 43 million. In addition, the definition considers capital and/or ownership ties between SMEs and other enterprises which may influence the final level of the criteria adopted for the analysis of company size.

The classification criteria of micro, small and medium-sized enterprises are the basis for the substantive identity of small business (Nicolescu, 2009; Storey \& Greene, 2010) reflected in OLC models dedicated to SMEs. Lester, Parnell and Carraher (2003) point out that these models should be based on the use of certain sub-stages that express the specificity of small business. In their opinion, a description of SMEs' development processes is best 
reflected in the initial stages of the life cycle, to which special attention should be paid in the case of OLC models dedicated to small business. The remaining key distinguishing substantive features of stage lifecycle models of SMEs include:

- complementing and expanding the small business start-up stage through the inclusion of the conceptual stage (pre-emergence), in which the preparation of the concept of market activities of the new company occurs (Felsenstein \& Swartz, 1993);

- emphasising the role of entrepreneurship and the business owner's attitude as key determinants of success in the small business life cycle (Adizes, 1988);

- rejecting an absolutely deterministic course of the life cycle and accepting a non-linear course of the stages that assume the return to the initial stages (Churchil \& Lewis, 1983) as well as the above average growth bypassing the intermediate stages (Granlund \& Taipaleenm, 2005);

- acknowledging the possibility of the use of reconfiguration and organisational renewal to counter crisis phenomena, prevent the decline stage and allow an effective continuation of business activity (Belussi \& Sedita, 2009);

- considering the possibility of leaving the population of SMEs by separating the ownership and management, or by a merger with another company, aimed at further market expansion already in the population of LEs (Jones, 2009).

Based on the existing OLC models and considering the criticisms formulated against these models (Phelps, Adams \& Bessant, 2007), an original stage of the dynamics and statics model of SMEs' life-cycle was proposed. Its substantive scope covers eight stages relating to the qualitative specificity of small business (Matejun, 2013):

- the pre-emergence stage of conceptual nature, aimed at the decision about setting up the company;

- the emergence stage, in which first investments and first attempts at developing and commercialising the company's market offer based on entrepreneurial activity are made;

- the survival stage, which is a period of the first market verification of the company and of a challenge related to ensuring the required level of profitability and liquidity;

- the dynamic growth stage, in which the following quantitative growth indicators significantly increase: turnover, the level of employment or the number of contractors, accompanied by the introduction of proactive qualitative changes in the company;

- the separation and expansion stage, in which important expansion activities in the area of market, product or investment are carried out, and the authority is often passed into the hands of professional managers;

- the stabilisation stage, in which the dynamics of business growth is reduced, accompanied by stabilisation of financial indicators, reduction in investment and growth of the organisation;

- the revitalisation stage, characterised by a dynamic and proactive approach to the company's further development based on the introduction of significant changes in the company's structure, business strategy and market offer;

- the decline stage, characterised by a rather permanently reduced level of efficiency and effectiveness, as well as negative financial results, which may lead to the collapse of the company.

An innovative approach expressed in the proposed model assumes, on the one hand, a clear substantive differentiation of the life cycle stages, and, on the other hand, includes the search for similarities between the different stages. These similarities express a specific approach to business development and business activity. It is worth noting that some of the stages are characterised by a proactive approach to business activity and focusing efforts on the market, investment and development processes. Such stages are set out in the model as the dynamic development stages. Their opposites are the static stages, characterised by more conservative and stable actions focused on current activities and ensuring the continuity of the company. Masurel and van Montfort (2006) came to similar conclusions considering the similarity of the life cycle stages in relation to such indicators as sales diversification, diversity of the workforce, or productivity. Their analysis of similarities, however, concerns only the initial stages, as well as the business maturity and decline stages.

In the proposed S\&D life cycle model, all the stages are divided into static and dynamic ones from the point of view of the proactive approach to development activity. However, this division is not absolute as it includes the identification of specific systems of static and dynamic antitheses, as shown in Tab. 1.

At the same time, the proposed S\&D life cycle model assumes a departure from the deterministic approach, typical of previous models, according to which a company passes linearly through all the sub- 
Tab. 1. Static and dynamic antitheses in the proposed S\&D life cycle model

\begin{tabular}{|l|c|l|}
\hline \multicolumn{1}{|c|}{ StATIC STAGES } & ANTITHESIS & \multicolumn{1}{c|}{ DYNAMIC STAGES } \\
\hline $\begin{array}{l}\text { The pre-emergence stage } \\
\text { The survival stage }\end{array}$ & $\leftrightarrow$ & The emergence stage \\
\hline The stabilisation stage & $\leftrightarrow$ & The dynamic growth stage \\
\hline The decline stage & $\leftrightarrow$ & $\begin{array}{l}\text { The separation and expansion stage } \\
\text { The revitalisation stage }\end{array}$ \\
\hline
\end{tabular}

Fig. 1 shows the graphical form of the proposed S\&D life cycle model.

The proposed model can, therefore, be a useful and powerful managerial tool explaining the specificity of causes and determinants, as well as the course of small business sequent development stages. The linear process of development only applies to the first three stages, and then SME managers can to a large extent control the development of enterprises with the right concepts and management methods aimed at the effective use of internal resources and the potential of the external environment in business development processes. Thus, different combinations of the order of the life cycle stages are possible. Errors in the management area will mostly result in shifting in the direction of the static stages, while effective management solutions will provide a basis for growing dynamics of development processes. As a result, the model does not assume a single, universal development path, as each company has its own, unique life cycle. Although the model primarily includes the specificity of small business, it also considers the possibility of a company's transition to the group of large enterprises. The subsequent growth is most often the continuation of the dynamic growth stage or the separation and expansion stage. The explanation of the further stages of development of thus transited enterprises requires the use of other OLC models which consider the specificity of LEs. development processes. A key challenge in this respect, however, is confirmation of theoretical assumptions concerning the diversity of selected determinants and effects of SME development, considering the dynamics and statics resulting from the proposed S\&D life cycle model. Since the model assumes that the dynamic stages are characterised by a proactive approach to development processes, the hypothesis $\mathrm{H} 1$ was formulated. It assumes that SMEs operating in the dynamic stages of the S\&D life cycle model are characterised by higher levels of the potential of internal development factors and more positively perceive the potential of their business environment. Their higher growth potential should be reflected in the results of the conducted business activity. Based on the above, the hypothesis $\mathrm{H} 2$ was formulated. It assumes that SMEs operating in the dynamic stages of the S\&D life cycle model achieve higher business performance than SMEs operating in the static stages. The empirical studies presented further in the paper serve the verification of the formulated hypotheses.

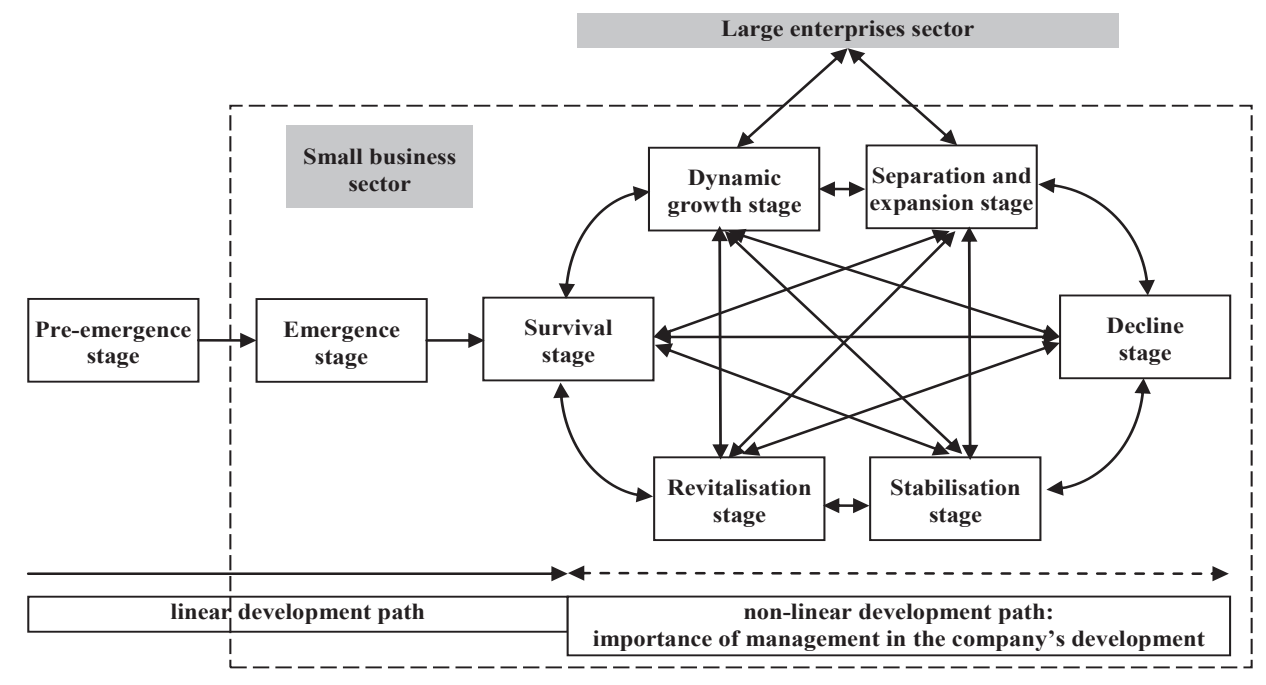

Fig. 1. Graphical form of the proposed S\&D life cycle model 


\section{RESEARCH METHODS}

To present the possible use of the S\&D life cycle model to describe and interpret the course of small business development processes, a survey was conducted on a sample of 1,741 SME companies. The CSAQ - Computerised Self-Administered Questionnaire - was used as the research technique (Bryman \& Bell, 2015). The research tool was the original survey questionnaire available to respondents on www.questionpro.com.

In view of the fundamental importance of small business for the socio-economic development of the European Union, the study covered 22 selected countries in the EU: Austria, Belgium, Bulgaria, Croatia, the Czech Republic, Denmark, Finland, France, Germany, Great Britain, Greece, Hungary, Italy, Lithuania, the Netherlands, Poland, Portugal, Romania, Slovakia, Slovenia, Spain and Sweden. Statistical data from European Union (2016) and the European Commission (2016) show that there are more than 21 million enterprises in this area, of which over $98 \%$ are SMEs. According to the World Bank indicators (2016), the research area covers more than 4 million sq. $\mathrm{km}$ (more than $95 \%$ of the area of the EU) and is inhabited by nearly 500 million people ( $98 \%$ of the population of the $\mathrm{EU}$ ).

The size of the companies surveyed was established based on the answers provided by the respondents to the questions in the survey questionnaire concerning annual average employment levels (FTE), the level of turnover (LoT), and the balance sheet total (BST). The quantitative levels for each of the criteria were adopted based on the formal, uniform SME definition provided by the European Commission (2015) and applicable throughout the European Union. As a result, it was possible to determine 1,183 micro companies, 399 small companies and 159 medium-sized companies in the sample. Also, all the surveyed entities were autonomous enterprises, i.e. they were completely independent in terms of capital and/or ownership from other entities or had one or more minority partnerships (each less than 25\%) with other enterprises.

Most of the companies surveyed operate as sole proprietorships run by individual owners (45\%) or as limited liability companies (35\%). These are companies operating primarily in the service sector $(60 \%)$, fewer in the manufacturing (21\%) or trade sectors (19\%). Most of the surveyed companies (73\%) are active at least in the domestic market. The sample included entities with a relatively long period of market activity, of more than 20 years $(36 \%)$ or from 5 to 10 years (21\%). Detailed characteristics of the companies surveyed are shown in Tab. 2.

The empirical material concerning the surveyed SMEs was collected based on the opinions and observations of the respondents. The respondents were primarily business owners (74\%), higher level managers (19\%) or employees authorised and legitimised by the management to participate in the study (7\%).

Tab. 2. Detailed characteristics of the surveyed SMEs

\begin{tabular}{|c|c|c|c|c|c|}
\hline COMPANY SIZE & $\mathbf{N}$ & [\%] & LEGAL FORM OF THE COMPANY & N & [\%] \\
\hline $\begin{array}{l}\text { Micro (up to } 9 \text { employees, LoT and BST up to } \\
\text { EUR } 2 \text { million) }\end{array}$ & 1183 & 67.9 & Individual company & 775 & 44.5 \\
\hline $\begin{array}{l}\text { Small (up to } 49 \text { employees, LoT and BST up to } \\
\text { EUR } 10 \text { million) }\end{array}$ & 399 & 22.9 & Private partnership & 232 & 13.3 \\
\hline $\begin{array}{l}\text { Medium (up to } 249 \text { employees, LoT up to } \\
\text { EUR } 50 \text { million and BST up to EUR } 43 \text { million) }\end{array}$ & 159 & 9.1 & Limited liability company & 614 & 35.3 \\
\hline SECTOR OF MARKET OPERATIONS & $\mathbf{N}$ & [\%] & Joint stock company & 96 & 5.5 \\
\hline Service & 1043 & 59.9 & Cooperative & 15 & 0.9 \\
\hline Trade & 335 & 19.2 & Foundation & 7 & 0.4 \\
\hline Production & 363 & 20.9 & Other & 2 & 0.1 \\
\hline COMPANY AGE & $\mathbf{N}$ & [\%] & RANGE OF MARKET OPERATIONS & $\mathbf{N}$ & [\%] \\
\hline Up to 5 years & 198 & 11.4 & Local & 116 & 6.7 \\
\hline Over 5 to 10 years & 368 & 21.1 & Regional & 347 & 19.9 \\
\hline Over 10 to 15 years & 305 & 17.5 & National & 676 & 38.8 \\
\hline Over 15 to 20 years & 240 & 13.8 & International & 479 & 27.5 \\
\hline Over 20 years & 630 & 36.2 & Global & 123 & 7.1 \\
\hline
\end{tabular}


The questions were mostly answered by men (70\%), aged 31 to 40 years (30\%) or over 50 years $(35.5 \%)$, with higher education (81\%), technical education $(40 \%)$ or economic/management education (26\%).

Based on the empirical material collected, a statistical analysis was conducted using IBM SPSS Statistics (Field, 2014). The following statistical methods were used (Swift \& Piff, 2014; Weinberg \& Abramowitz, 2015): count analysis, mean, Spearman's (rs) correlation coefficient and its significance test, Student's t-test with the additional inclusion of Levene's Test of Equality of Variances. To measure most variables, the VAS - Visual Analogue Scale - was used (Reips \& Funke, 2008). The level of reliability of the adopted measurement scales was assessed with the use of Cronbach's alpha coefficient (Cronbach \& Shavelson, 2004), for which an acceptable level in the range from 0.7 to 0.9 was adopted. To assess the strength of the interdependence of the phenomena, an approach based on the proposal formulated by Cohen (1992) was used, taking as the thresholds of the linear correlation coefficient the following correlation levels: 0.1 - weak; 0.3 - medium; 0.5 - strong, 0.7 - very strong.

\section{RESEARCH RESULTS AND DISCUS- SION}

In the first stage of empirical work, the range of occurrence of static and dynamic stages of the life cycle in the studied sample was analysed. Their identification was made based on indications (declarations) of the respondents who in the survey questionnaire were to indicate one stage which was best suited to the current market situation of their companies. To increase the precision of the responses, each stage was accompanied by a description corresponding directly to its theoretical characteristics. Since the study involved only functioning companies, the range of the S\&D life cycle model was narrowed down to 7 stages, excluding the pre-emergence stage from the research. The respondents frequently pointed out that the companies surveyed were in the stabilisation stage $(29 \%)$ or the dynamic growth stage (26\%). Most of the respondents declared operating in the static stages of the life cycle (53\%), but small and medium-sized companies more often indicated operating in the dynamic stages. The results indicate that the dynamics of the life cycle stages is, therefore, positively and significantly related to the size of the companies surveyed, $\mathrm{rs}(\mathrm{N}=1741)=0.14$, $\mathrm{p}<0.01$. The level of correlation indicates a very weak relationship between these variables. Detailed information on the declared life cycle stages of the companies surveyed, including the breakdown into the static and dynamic stages, is shown in Tab. 3.

The further part of the research focused on the description and interpretation of selected determinants and effects of development processes in the companies surveyed with the use of dynamics and statics resulting from the life cycle stages. The following areas were chosen for the analysis of development determinants:

- the business owner's entrepreneurship, which was established based on the classical approach to defining entrepreneurship proposed by Roberts et al. (2006) and Hisrich, Peters and Shepherd (2016). For its operationalisation, a synthetic index (4 items) was used including the focus on the identification of market opportunities, openness to cooperation with the environment, the owner's positive self-assessment and convic-

Tab. 3. Life cycle stages in the companies surveyed according to the S\&D model

\begin{tabular}{|c|c|c|c|c|c|c|c|c|}
\hline \multirow{2}{*}{ LIFE CYCLE STAGE } & \multicolumn{2}{|c|}{ TOTAL IN THE SAMPLE } & \multicolumn{2}{|c|}{ MICRO COMPANIES } & \multicolumn{2}{|c|}{ SMALL COMPANIES } & \multicolumn{2}{|c|}{ MEDIUM COMPANIES } \\
\hline & $\mathbf{N}$ & [\%] & $\mathbf{N}$ & [\%] & $\mathbf{N}$ & [\%] & $\mathbf{N}$ & [\%] \\
\hline Emergence stage & 32 & 2 & 30 & 3 & 2 & 1 & 0 & 0 \\
\hline Survival stage & 305 & 18 & 259 & 22 & 39 & 10 & 7 & 4 \\
\hline Dynamic growth stage & 447 & 26 & 278 & 23 & 114 & 29 & 55 & 35 \\
\hline Separation and expansion stage & 50 & 3 & 17 & 1 & 18 & 5 & 15 & 9 \\
\hline Stabilisation stage & 499 & 29 & 320 & 27 & 136 & 34 & 43 & 27 \\
\hline Revitalisation stage & 288 & 17 & 178 & 15 & 73 & 18 & 37 & 23 \\
\hline Decline stage & 120 & 7 & 101 & 9 & 17 & 4 & 2 & 1 \\
\hline Static stages in total: & 924 & 53 & 680 & 57 & 192 & 48 & 52 & 33 \\
\hline Dynamic stages in total: & 817 & 47 & 503 & 43 & 207 & 52 & 107 & 67 \\
\hline
\end{tabular}


tion about the effectiveness of actions undertaken, as well as taking calculated business risks. The individual items were assessed using the VAS in the range from 0 (completely does not apply to the owner) to 100 (fully applies to the owner). The level of alpha Cr. for this variable amounted to 0.868 ;

- organisational flexibility, as one of the key factors of small business development. For its operationalisation, a synthetic index (4 items) was used based on Verdú-Jover, Lloréns-Montes and García-Morales (2006) and including the ability to modify the organisational and employment structure depending on development needs, having a resource surplus that allows to carry out dynamic development activities aimed at anticipating market trends and exploiting market opportunities. The individual items were assessed using the VAS in the range from 0 (completely does not apply to the company) to 100 (fully applies to the company). The level of alpha $\mathrm{Cr}$. for this variable amounted to 0.829 ;

- involvement in innovative activities, i.e. the ability to conduct innovative activities. For its operationalisation, a synthetic index (3 items) was used based on Edwards, Delbridge and Munday (2005) and Ahedo (2010) including the focus on innovative activities, an adaptation of innovative activities conducted to market needs, as well as the level of creative attitudes and behaviour of company employees. The individual items were assessed using the VAS in the range from 0 (completely does not apply to the company) to 100 (fully applies to the company). The level of alpha Cr. for this variable amounted to 0.754 ;

- perceived conditions of the small business environment, described with the use of two selected simple indicators: (1) intensity of competition in the industry, and (2) prospects of the industry development. Each one was evaluated using the VAS in the range from 0 (very low level) to 100 (very high level). Also, the respondents were asked about the competition arena in which the company operates (Porter, 2008) with the possibility of indicating (1) a market niche or (2) a wide arena of competition.

The assessment of development effects includes the company's performance, which was determined based on proposals by Murphy, Trailer and Hill (1996) as well as Aragón-Sánchez and Sánchez-Marín (2005), assuming the inclusion of 2 dimensions, namely, quantitative and qualitative. For its operationalisation, a synthetic index (8 items) was used including the level of revenue, return on investment, market share, productivity, quality and the ability to expand the offer of products and services, teamwork and CSR. The individual items were compared to the performance of major competitors (Koh et al., 2007) and assessed on the VAS scale in the range from 0 (much worse than competitors) to 100 (much better than competitors). The level of alpha Cr. for this variable amounted to 0.798 . The construction of this index also allowed the determination of two subvariables: quantitative and qualitative business performance. Tab. 4 shows descriptive statistics for each of the determinants and effects of development processes in the companies surveyed.

The next part of the study analysed the existence of differences in the assessment of individual development determinants and processes of the companies surveyed from the point of view of dynamics of the life cycle stages. Student's t-test considering Levene's Test of Equality of Variances was used, and the results are presented in Tab. 5 .

Tab. 4. Descriptive statistics of the analysed determinants and effects of development processes of the surveyed companies

\begin{tabular}{|c|c|c|c|c|}
\hline VARIABLE & TOTAL IN THE SAMPLE & MICRO COMPANIES & SMALL COMPANIES & MEDIUM COMPANIES \\
\hline Owner's entrepreneurship & 71 & 70 & 74 & 79 \\
\hline Organisational flexibility & 52 & 50 & 56 & 60 \\
\hline Involvement in innovative activities & 55 & 54 & 57 & 63 \\
\hline Intensity of competition in the industry & 74 & 74 & 73 & 76 \\
\hline Prospects of industry development & 62 & 61 & 65 & 66 \\
\hline Activity in a market niche [\%] & 39 & 42 & 36 & 30 \\
\hline Activity in a wide arena of competition [\%] & 61 & 58 & 64 & 70 \\
\hline Business performance & 61 & 60 & 63 & 66 \\
\hline Quantitative business performance & 49 & 47 & 52 & 58 \\
\hline Qualitative business performance & 68 & 68 & 70 & 71 \\
\hline
\end{tabular}


Tab. 5. Comparison of development determinants and processes of the companies surveyed from the point of view of dynamics and statistics of the life cycle stages

\begin{tabular}{|c|c|c|c|c|c|c|c|}
\hline \multirow{3}{*}{ VARIABLE } & \multicolumn{2}{|c|}{ LEVENE'S TEST } & \multicolumn{5}{|c|}{ T-TEST FOR EQUALITY OF MEANS } \\
\hline & \multirow{2}{*}{ EQUAL VARIANCES } & \multirow{2}{*}{$\mathbf{F}$} & \multirow{2}{*}{$\mathbf{T}$} & \multirow{2}{*}{ DF } & \multicolumn{2}{|c|}{ MEAN FOR STAGES: } & \multirow{2}{*}{$\begin{array}{c}\text { MEAN } \\
\text { DiffERENCE }\end{array}$} \\
\hline & & & & & STATIC & DYNAMIC & \\
\hline $\begin{array}{l}\text { Owner's } \\
\text { entrepreneurship }\end{array}$ & not assumed & $13.47^{* *}$ & $-9.50 * *$ & 1737 & 66.52 & 77.06 & -10.54 \\
\hline Organisational flexibility & assumed & 3.15 & $-12.58^{* *}$ & 1739 & 45.18 & 60.32 & -15.14 \\
\hline $\begin{array}{l}\text { Involvement } \\
\text { in innovative activities }\end{array}$ & assumed & 0.11 & $-14.16^{* *}$ & 1739 & 47.83 & 63.49 & -15.66 \\
\hline $\begin{array}{l}\text { Intensity of competition } \\
\text { in the industry }\end{array}$ & assumed & 2.23 & $2.52^{*}$ & 1739 & 75.11 & 72.18 & 2.92 \\
\hline $\begin{array}{l}\text { Prospects of industry } \\
\text { development }\end{array}$ & not assumed & $7.07 * *$ & $-12.03 * *$ & 1737 & 55.82 & 69.59 & -13.77 \\
\hline Competition arena & not assumed & $29.15^{* *}$ & $2.86^{* *}$ & 1700 & 1.64 & 1.57 & 0.07 \\
\hline Business performance & assumed & 0.05 & $-10.81 * *$ & 1739 & 57.70 & 65.53 & -7.82 \\
\hline $\begin{array}{l}\text { Quantitative business } \\
\text { performance }\end{array}$ & assumed & 0.15 & $-10.47 * *$ & 1739 & 45.06 & 54.28 & -9.23 \\
\hline $\begin{array}{l}\text { Qualitative business } \\
\text { performance }\end{array}$ & assumed & 0.39 & $-8.33 * *$ & 1739 & 65.19 & 72.17 & -6.98 \\
\hline
\end{tabular}

* significant at $0.05 ; *$ significant at 0.01 . Student's t-test for equality of means; Levene's test.

The results of the comparison indicate that companies in the static and dynamic stages of the life cycle differ significantly in terms of assessment of the analysed determinants and effects of small business development processes. Companies operating in the dynamic life-cycle stages are run by more enterprising owners who are actively focused on the identification of market opportunities through cooperation and building positive relations with the environment. These entrepreneurs can and like taking business risk, using appropriate calculation and optimisation of its level. They are also characterised by positive self-assessment and higher effectiveness of operation than business owners of companies in the static stages of the life cycle.

Higher levels of flexibility and involvement in innovative activities are also important features of enterprises operating in the dynamic stages of the life cycle. Flexibility as one of the basic determinants of small business competitiveness requires an increased level of resources allowing their dynamic allocation for development activities. This confirms, therefore, the existence of higher levels of SME resources in the dynamic stages compared to the static ones. Anticipating market trends and exploiting market opportunities, which promotes greater involvement in innovative activities in the dynamic stages of the life cycle, are also important components of flexibility.
The phenomenon of more positive perception and better use of the potential of the business environment also occurs in the dynamic stages. Companies operating in such stages often build their market position in market niches, adopting a strategy of diversification. Due to this fact, they assess the level of competition as lower and assess prospects for the industry in which they operate more positively. The results obtained therefore fully confirm the hypothesis $\mathrm{H} 1$ according to which SMEs operating in the dynamic stages of the S\&D life cycle model are characterised by higher levels of the potential of internal development factors and perceive the potential of the business environment more positively than SMEs operating in the static stages.

The recognised internal determinants and the positive perception of the business environment translate into the higher business performance of SMEs operating in the dynamic stages of the life cycle. Although the companies surveyed generally assess their qualitative results better than quantitative ones, the companies operating in the dynamic stages of the life cycle achieve relatively higher growth of quantitative results than qualitative ones. This confirms, therefore, also relatively higher levels of resources of these entities, resulting in the ability to initiate and pursue innovative and market activities to a much greater extent than in the case of companies operating in the static stages of the life cycle. These 
results, therefore, fully confirm the hypothesis $\mathrm{H} 2$, which assumes that SMEs operating in the dynamic stages of the S\&D life cycle model achieve higher business performance than SMEs operating in the static stages.

\section{LIMITATIONS AND FURTHER DIRECTIONS IN THE USE OF THE S\&D LIFE CYCLE MODEL}

When considering the results obtained and formulating cognitive conclusions and applications, limitations of the research should be considered (Geletkanycz \& Tepper, 2012). First, these include methodological limitations associated with the use of cross-sectional studies (Sreejesh, Mohapatra \& Anusree, 2014) which do not allow to capture dynamic changes taking place in companies over time. This makes the identification and description of the transformation taking place in the life cycle of the surveyed SMEs difficult. Conducting retrospective longitudinal studies (Rose, Spinks \& Canhoto, 2015) could be an answer to the identified limitations, allowing more precise identification and assessment of determinants and effects of SME development in the individual stages of the life cycle.

Another limitation is high subjectivity of evaluations and opinions provided by the respondents resulting from the use of survey research method (Beam, 2012). The method makes it difficult to obtain proper responses, accurately reflecting the organisational reality in the companies surveyed. The high level of complexity and multidimensionality of the constructs analysed should also be considered. Due to the methodological limitations, their operationalisation included only selected indicators and was simplified.

Considering the results obtained, the research should be continued. Interesting directions of further empirical analysis can include the identification and assessment of the evolutionary nature of the proposed S\&D life cycle model. In this area, it is worth focusing on key factors determining the transition from one stage of the life cycle to the next, with particular regard to the transition between the static and dynamic stages of the life cycle. In the area of methodology, one should consider the preparation of a measuring scale allowing more precise and objective selection of the stage of the life cycle best suited to the organisational situation of the company concerned.

\section{CONCLUSIONS}

The paper proposes an original, 8-stage statics and dynamics model in the small business life cycle (S\&D life cycle model). It constitutes a novel approach, based on the current theoretical achievements, to determination and classification of the life cycle stages based on the dynamics of development processes, market activity, or the investment scope. In this model, the static stages, in which development efforts focus on current activities and ensuring the continuity of the survival of a given company, form the first group. These include the following stages: the pre-emergence, survival, stabilisation and decline ones. Their antitheses are the dynamic stages characterised by an active or even proactive approach to development, investment and market processes. These include the following stages: emergence, dynamic growth, separation and expansion as well as revitalisation. The proposed model reduces the disadvantages of the existing theoretical approaches through the rejection of the deterministic nature of the described development paths. At the same time, it allows the identification and understanding of internal and external determinants and effects of small business development activity.

The results of the empirical research conducted on a sample of 1,741 micro, small and medium-sized enterprises from 22 countries of the European Union provide the confirmation. They indicate the existence of significant differences between companies operating in the static and dynamic stages of the life cycle in the following three main areas:

- in the area of internal development determinants, companies operating in the dynamic life-cycle stages are run by more enterprising owners, show a higher level of organisational flexibility and greater involvement in innovative activities;

- in the area of external development determinants, companies operating in the dynamic stages of the life cycle more often exploit the potential resulting from activities in market niches, thus limiting the intensity of competition in the industry. Entrepreneurs from such companies also more positively assess the potential of the business environment related to the better assessment of industry development prospects; 
- in the area of effects of development processes, companies operating in the dynamic stages of the life cycle achieve better business performance in terms of qualitative as well as quantitative results.

The presented theoretical approach and the obtained empirical research results provide new conclusions in the discussion on the cognitive value of the small business life cycle model (Tendai, 2013; Tam \& Gray, 2016). Based on these considerations, it can be concluded that the S\&D life cycle model allows to describe the potential of internal development determinants and the manner of perception of the potential of the small business environment. At the same time, it also provides subsequent evidence explaining the volatility of business performance of micro, small and medium-sized enterprises.

\section{ACKNOWLEDGEMENTS}

The presented research was conducted as an analysis carried out under the research project No. 2015/17/B/ HS4/00988 financed by the National Science Centre, Poland.

\section{LITERATURE}

Adizes, I. (1988). Corporate lifecycles. How and why corporations grow and what to do about it. Englewood Cliffs, USA: Prentice Hall.

Ahedo, M. (2010). Exploring the innovative potential of SMEs in Spain. Transfer: European Review of Labour and Research, 16(2), 197-209. doi: 10.1177/10 24258910364307

Aragón-Sánchez, A., \& Sánchez-Marín, G. (2005). Strategic orientation, management characteristics, and performance: a study of Spanish SMEs. Journal of Small Business Management, 43(3), 287-308. doi: 10.1111/ j.1540-627X.2005.00138.x

Autio, E. (2016). Entrepreneurship support in Europe: Trends and challenges for EU policy. London, England: Imperial College Business School.

Beam, G. (2012). The problem with survey research. New Brunswick, USA: Transaction Publishers.

Belussi, F., \& Sedita, S. R. (2009). Life cycle vs. multiple path dependency in industrial districts. European Planning Studies, 17(4), 505-528. doi: 10.1080/09654310802682065

Bryman, A., \& Bell, E. (2015). Business research methods. Oxford, England: Oxford University Press.
Churchill, N., \& Lewis, V. (1983). The five stages of small business growth. Harvard Business Review, 61(3), 30-50.

Cohen, J. (1992). A power primer. Psychological Bulletin, 112(1), 155-159.

Cronbach, L. J., \& Shavelson, R. J. (2004). My current thoughts on coefficient alpha and successor procedures. Educational and Psychological Measurement, 64(3), 391-418.

Edwards, T., Delbridge, R., \& Munday, M. (2005). Understanding innovation in small and medium-sized enterprises: a process manifest. Technovation, 25(10), 1119-1127. doi: 10.1016/j.technovation.2004.04.005

European Commission. (2015). User guide to the SME definition. Luxembourg: Publications Office of the European Union.

European Commission. (2016). SME Performance Review. Retrieved from: https://ec.europa.eu/growth/smes/ business-friendly-environment/performancereview-2016_en

European Union. (2016). Eurostat. Retrieved from: http:// epp.eurostat.ec.europa.eu

Felsenstein, D., \& Swartz, D. (1993). Constraints to small business development across the life cycle: Some evidence from peripheral areas in Israel. Jerusalem, Israel: Hebrew University of Jerusalem.

Field, A. (2014). Discovering statistics using IBM SPSS Statistics. London, England: SAGE Publications.

Floyd, D., \& McManus, J. (2005). The role of SMEs in improving the competitive position of the European Union. European Business Review, 17(2), 144-150. doi: 10.1108/09555340510588011

Geletkanycz, M., \& Tepper, B. J. (2012). From the editors: Publishing in AMJ - part 6: discussing the implications. Academy of Management Journal, 55(2), 256260. doi: $10.5465 / \mathrm{amj} .2012 .4002$

Granlund, M., \& Taipaleenm, J. (2005). Management control and controllership in new economy firms - a life cycle perspective. Management Accounting Research, 16(1), 21-57. doi: 10.1016/j.mar.2004.09.003

Griliches, Z. (1957). Hybrid corn: An exploration in the economics of technological change. Econometrica, 25(4), 501-522.

Hisrich, R. D., Peters, M. P., \& Shepherd, D. A. (2016). Entrepreneurship. New York, USA: McGraw-Hill Education.

Jackson, J. H., \& Morgan, C. P. (1982). Organization theory. A macro perspective for management. London, England: Prentice Hall.

Jones, N. (2009). SME's life cycle - steps to failure or success? AU-GSB e-Journal, 2(2), 3-14.

Koh, L., Demirbag, M., Bayraktar, E., Tatoglu, E., \& Zaim, S. (2007). The impact of supply chain management practices on performance of SMEs. Industrial Management \& Data Systems, 107(1), 103-124. doi: 10.1108/02635570710719089 
Kushnir, K., Mirmulstein, M. L., \& Ramalho, R. (2010). Micro, small, and medium enterprises around the world: how many are there, and what affects the count? Washington, USA: MSME Country Indicators, The World Bank, \& International Finance Corporation.

Lester, D. L., Parnell, J. A., \& Carraher, S. (2003). Organizational life cycle: A five-stage empirical scale. International Journal of Organizational Analysis, 11(4), 339-354. doi: 10.1108/eb028979

Levie, J. D., \& Lichtenstein, B. B. (2010). A terminal assessment of stages theory: Introducing a dynamic states approach to entrepreneurship. Entrepreneurship Theory and Practice, 34(2), 317-350. doi: 10.1111/j.1540-6520.2010.00377.x

Lukács, E. (2005). The economic role of SMEs in world economy, Especially in Europe. European Integration Studies, 4(1), 3-12

Mansfield, E. (1961). Technical change and the rate of imitation. Econometrica, 29(4), 741-766.

Masurel, E., \& Van Montfort, K. (2006). Life cycle characteristics of small professional service firms. Journal of Small Business Management, 44(3), 461-473. doi: 10.1111/j.1540-627X.2006.00182.x

Matejun, M. (2013). Instruments supporting development in the life cycle of small and medium-sized enterprises. International Journal of Economic Sciences, 2(1), 40-60.

Murphy, G. B., Trailer, J. W., \& Hill R. C. (1996). Measuring performance in entrepreneurship research. Journal of Business Research, 36(1), 15-23. doi: 10.1016/01482963(95)00159-X

Nicolescu, O. (2009). Main features of SMEs organisation system. Review of International Comparative Management, 10(3), 405-413.

Phelps, R., Adams, R., \& Bessant, J. (2007). Life cycles of growing organizations: A review with implications for knowledge and learning. International Journal of Management Reviews, 9(1), 1-30. doi: 10.1111/j.1468-2370.2007.00200.x

Porter, M. E. (2008). Competitive advantage: Creating and sustaining superior performance. New York, USA: Free Press.

Reips, U. D., \& Funke, F. (2008). Interval-level measurement with visual analogue scales in internet-based research: VAS Generator. Behavior Research Methods, 40(3), 699-704.

Roberts, M., Stevenson, H., Sahlman, W., Marshall, P., \& Hamermesh, R. (2006). New business ventures and the entrepreneur. New York, USA: McGraw-Hill Education.

Rose, S., Spinks, N., \& Canhoto, A. I. (2015). Management research: Applying the principles. New York, USA: Routledge.

Samuel, Y. (2012). Organizational pathology: Life and death of organizations. New Brunswick, USA: Transaction Publishers.

Sreejesh, S., Mohapatra, S., \& Anusree, M. R. (2014). Business research methods: An applied orientation. London, England: Springer Science \& Business Media.
Storey, D. J., \& Greene, F. J. (2010). Small business and entrepreneurship. Harlow, England: Pearson Education Limited.

Swift, L., \& Piff, S. (2014). Quantitative methods: for business, management and finance. Hampshire, England: Palgrave Macmillan.

Tam, S., \& Gray, D. E. (2016). What can we learn from the organizational life cycle theory? A conceptualization for the practice of workplace learning. Journal of Management Research, 8(2), 18-29. doi: 10.5296/jmr. v8i2.9093

Tendai, C. (2013). Networks and performance of small and medium enterprises (SMEs) in different stages of the life cycle: A case study of a small business in the Netherlands. Journal of Communication, 4(2), 89-94.

The World Bank. (2016). Indicators: Agriculture \& Rural Development. The World Bank Data. Retrieved from: http://data.worldbank.org/indicator

Verdú-Jover, A. J., Lloréns-Montes, F. J., \& García-Morales, V. J. (2006). Environment-Flexibility coalignment and performance: an analysis in large versus small firms. Journal of Small Business Management, 44(3), 334-349. doi: 10.1111/j.1540-627X.2006.00175.x

Weinberg, S. L., \& Abramowitz, S. K. (2015). Statistics using SPSS: An integrative approach. Cambridge, England: Cambridge University Press. 